Morphology, pasting and thermal properties of microwave-assisted cassava starch- stearic acid complex

S.A. Oyeyinka, T.M. Afunso, A.A. Adeloye and S.S. Diarra
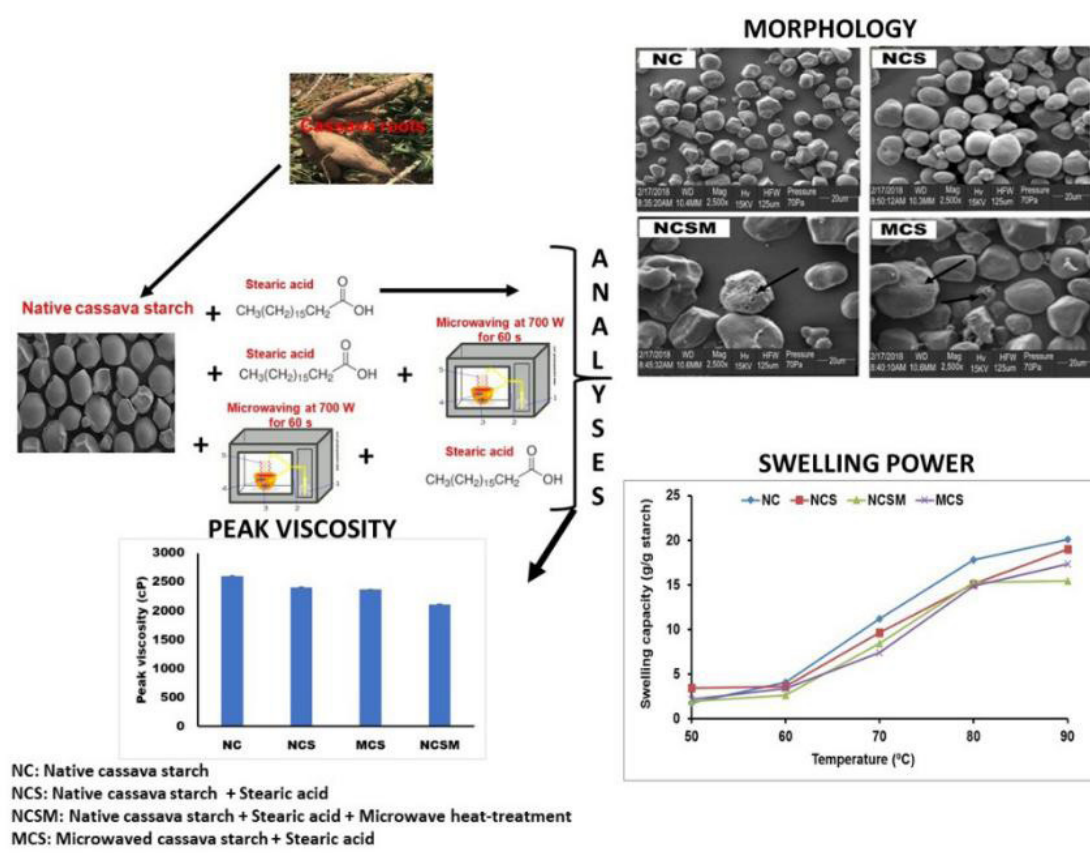

SWELLING POWER

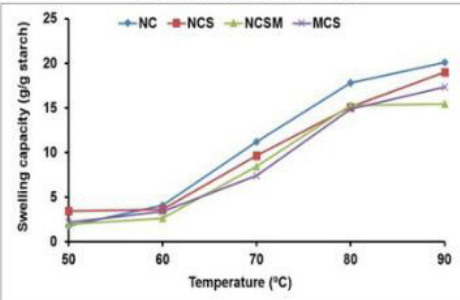

NCS: Native cassavastarch + Stearic acid

NCSM: Native cassava starch + Stearic acid + Microwave heat-treatment Temperature ('C)

\title{
Highlights
}

- Microwaving and stearic acid addition reduced the swelling power of cassava starch.

- Microwaving in combination with stearic acid showed a greater reduction in peak viscosity.

- Pasting of native or microwaved cassava starch with stearic acid produced type I amylose-lipid complexes. 


\title{
RESEARCH ARTICLE
}

\section{Morphology, pasting and thermal properties of microwave-assisted cassava starch- stearic acid complex}

\author{
S.A. Oyeyinka ${ }^{1,3,}$, T.M. Afunso ${ }^{1}$, A.A. Adeloye ${ }^{2}$ and S.S. Diarra ${ }^{3}$ \\ ${ }^{1}$ Department of Home Economics and Food Science, University of Ilorin, Ilorin, Nigeria. \\ ${ }^{2}$ Department of Animal Production, University of Ilorin, Ilorin, Nigeria. \\ ${ }^{3}$ School of Agriculture and Food Technology, University of the South Pacific, Apia, Samoa.
}

Received: 16/07/2019; Accepted: 22/06/2020

\begin{abstract}
In this study, the physicochemical properties of microwave-assisted cassava starch-stearic acid complex was investigated. The effects of the modification methods were assessed using a scanning electron microscope, differential scanning calorimeter and rapid visco analyser. Native cassava starch showed mostly polygonal shape with some granules irregular and round in shape. Native cassava starch with added stearic acid had slight changes in shape while microwaved cassava starch showed irregular and dented granules with pin-holes or fissures. Native cassava starch modified with stearic acid alone or microwaved cassava starch with added stearic acid showed decreased swelling power as compared to the native starch. Pasting properties of cassava starch were significantly affected by stearic acid addition or microwaving. Stearic acid addition alone reduced the peak viscosity slightly (approx. 7\%), adding stearic acid to microwaved cassava starch reduced the peak viscosity by approximately $9 \%$, while microwaving cassava starch-stearic acid mixture showed greater reduction in peak viscosity (approx. $19 \%$ ). Pasting of native or microwaved cassava starch with stearic acid resulted in the formation of type I amylose-lipid complexes, with melting temperatures ranging from approx. 92 to $1020 \mathrm{C}$. Microwaving can improve complexation of stearic acid with cassava starch to produce modified starch with higher thermal stability and increased final viscosity.
\end{abstract}

Keywords: Amylose-lipid complexes, Cassava starch, Stearic acid, Microwaving.

\section{INTRODUCTION}

Cassava (Manihot esculanta Crantz) is a root widely consumed in many parts of the world including Africa. It is a good source of starch, which may be explored in various industrial applications due to its remarkable characteristics such as high freeze-thaw stability, high paste viscosity and clarity which are advantageous for applications industrially (Nwokocha et al., 2009). Although cassava starch represents a valuable ingredient in food and pharmaceutical industries, in the native form, the starch is unsuitable for most industrial applications. This is because native starches generally they have poor resistance to processing conditions such as shear, $\mathrm{pH}$ and heat frequently encountered in the industry.

Hence, they must be modified to eliminate these shortcomings and to improve their physicochemical and functional properties (Kaur et al., 2012). According to Oyeyinka and Oyeyinka (2018), starch may be modified by chemical, physical, enzymatic genetic and a combination of these methods. Due to increased awareness of the relationship between diet and health, consumers are demanding foods with natural chemicals rather than synthetic ones. Hence, researchers are now focusing on the use of environmentally friendly method such as the use of natural chemicals e.g. lipids (Oyeyinka et al., 2018; Oyeyinka et al., 2017a) and physical methods such as microwaving (Lewandowicz et al., 2000; Oyeyinka et al., 2019).

Cassava starch has been chemically modified using lipids such as stearic acid (Maphalla and Emmambux, 2016; Schmidt et al., 2013; Varavinit et al., 2001) and physically by microwaving (Colman et al., 2014; Lewandowicz et al., 1997; Oyeyinka et al., 2019). Starch-lipid complexes also known as V-amylose complexes are important in food applications because they have been reported to reduce tendency towards retrogradation (Oyeyinka et al., 2016b), produce starch with slowly digestible property (Oyeyinka et al., 2017c) and enhanced final viscosity (D'silva et al., 2011; Oyeyinka et al., 2017c).

The interaction between starch and lipids is influenced by several factors including amylose content, lipid type, starch moisture content and complexation conditions. Due to the benefit of starch-lipid complexes, efforts are on-going to improve the degree of complexation of starch with lipids using different method such as extended pasting of starch with lipids (D'silva et al., 2011), increased incubation time of starch with lipids (Chang et al., 2014), use of high pressure homogenization (Meng et al., 2014a; Meng et al., 2014b; Oyeyinka et al., 2016a, 2016b) as well as a combination of physical and chemical methods (Oyeyinka et al., 2018).

Microwave in combination with chemical methods have been reportedly used in starch modification for improved functionality. For instance, Zhao et al. (2018) reported that microwave pretreated esterification improved the substitution degree, structural and physicochemical properties of potato starch esters. Furthermore, other authors reported that microwave-assisted rapid heating of 
starch is an effective method for increasing the production of starch acetate (Lin et al., 2017). Other studies found that microwaving alone altered the structure of starch granules (Lewandowicz et al., 2000) and created pin holes on granule surface (Luo et al., 2006; Oyeyinka et al., 2019). Hence, it is hypothesized that the pores created during microwaving may facilitate the movement of lipids into the starch granule interior during heating. Hence, this study investigated morphology, pasting and thermal properties of microwave-assisted cassava starch- stearic acid complex.

\section{MATERIALS AND METHODS}

Cassava roots (TMS 326) were harvested from University of Ilorin research farm, Ilorin, Kwara state, Nigeria. Stearic acid (STE) was purchased from Ninoflex chemical stores, Ikeja, Lagos state. All chemicals and solvents used were laboratory grade.

\section{Starch extraction}

Starch was extracted as previously reported (Osunsami et al., 1989). Cassava roots $(2 \mathrm{~kg}$ ) were peeled, washed and grated using a grating machine powered by Lister Diesel engine (5-1 6HP 650RPM, UK). The mash was submerged in water and sieving was done using a muslin cloth into a fresh bowl of potable water. The extract was left to settle for 24 hrs. After settling, the supernatant was disposed and fresh water (10 litres) was added to the sediment. The washing procedure was repeated five times until a clean white starch was obtained. Starch slurry was pressed in a muslin cloth to remove excess water and the starch sample was oven dried at $60{ }_{\circ} \mathrm{C}$ for $24 \mathrm{hrs}$. Dried samples were milled using a warring blender (Model: 8010S Torrington USA), sieved (sieve size: $(180 \mu \mathrm{m})$ and packaged in Ziplock bags prior to analyses.

\section{Microwaving of starch}

Starch was microwaved as previously reported except that a maximum time of $60 \mathrm{~s}$ was used (Oyeyinka et al., 2019). Briefly, the moisture content of the starch was adjusted to $30 \%$ with distilled water. The moistened starch was allowed to equilibrate for $2 \mathrm{~h}$, prior to heating. After equilibration, starch samples were sealed with perforated polyethylene foil (Macro Packaging, Ivychurch, Kent, UK) designed for microwave ovens. Starch was heated using a microwave (Model MEJ11K, LG, Kuala Lumpur, Malaysia) at $700 \mathrm{~W}$ output and a frequency of $2450 \mathrm{MHz}$ for $60 \mathrm{~s}$. After heating, the sample was allowed to cool at room temperature and stored at $4{ }_{0} \mathrm{C}$ until analysed.

\section{Incorporation of stearic acid into starch}

The complexing of stearic acid to the starch granules was done according to previous methods (Oyeyinka et al., 2017c). Cassava starch was suspended in minimum amount of ethanol containing $2 \%$ stearic acid. The suspension was stirred with a magnetic stirrer at $50^{\circ} \mathrm{C}$ for $1 \mathrm{hr}$ and then at room temperature for an additional $12 \mathrm{hr}$. Thereafter, the starch sample was oven dried and used immediately for subsequent analyses. Native cassava starch was treated the same way as the stearic acid treated starch.

\section{Swelling power}

Swelling power was determined as previously reported (Oyeyinka et al., 2015). Briefly, a 1\% starch suspension in water was heated for $30 \mathrm{~min}$ from 50 to $90 \circ \mathrm{C}$ with constant stirring. The suspension was centrifuged (model 5810R, Eppendorf International, Frankfurt, Germany) at $3400 \times \mathrm{g}$ for $20 \mathrm{~min}$ at $25_{\mathrm{o}} \mathrm{C}$ and the supernatant discarded. Swelling power was obtained by weighing the residue after centrifugation and dividing by the original weight of starch on a dry weight basis.

\section{Microscopy}

Starch granule morphology was studied using a scanning electron microscope (EVO 15 HD, CarL Zeiss, Jena, Germany) (Oyeyinka et al., 2019). Average starch granule size was determined from diameter of individual granules $(\mathrm{N}=50)$ on the basis of the scale bar provided on the captured scanning electron micrographs (Stevenson et al., 2006).

\section{Pasting properties}

The pasting properties of the starch samples were measured using a Rapid Visco-Analyzer (RVA 4500, Perten Instruments, Sydney, NSW, Australia). Briefly, $2.5 \mathrm{~g}$ of each sample was weighed and distilled water was added after accounting for the variation in moisture content of the microwaved samples. The mixture was agitated by mixing manually using a plastic paddle before inserting the canister into the instrument. Starch was stirred at $960 \mathrm{rpm}$ for $10 \mathrm{~s}$ before the shear input was decreased and held constant at $160 \mathrm{rpm}$ during the subsequent heating and cooling cycles. The peak viscosity, hot paste viscosity, cold paste viscosity, breakdown viscosity, peak time and pasting temperature of the samples were obtained from the instrument.

\section{Thermal properties}

Thermal property was examined according to a previously reported method (Oyeyinka et al., 2015). Briefly, pasted freeze-dried complexes starch $(3 \mathrm{mg}$ ) was directly weighed into an aluminum DSC pan and distilled water $(12 \mu \mathrm{l})$ added. Pans were hermetically sealed and equilibrated for $12 \mathrm{hrs}$. Samples were heated from 20 to $120^{\circ} \mathrm{C}$ at a rate of $10^{\circ} \mathrm{C} / \mathrm{min}$; an empty pan was used as reference. The onset temperature $\left(\mathrm{T}_{\mathrm{o}}\right)$, melting temperature $\left(\mathrm{T}_{\mathrm{m}}\right)$, conclusion temperature $\left(\mathrm{T}_{\mathrm{c}}\right)$ and melting enthalpy $\left(\Delta \mathrm{H}_{\mathrm{m}}\right)$ were obtained for the starch-lipid complexes.

\section{Statistical analysis}

Duplicate samples were prepared and analyses done in triplicate. Data was analysed using one-way analysis of variance (ANOVA) and means were compared using the Fisher Least Significant Difference (LSD) test $(\mathrm{p} \leq 0.05)$ using the Statistical Package for the Social Sciences (SPSS) Version 16.0 for Windows (SPSS Inc., Chicago, IL, USA). 


\section{RESULTS AND DISCUSSION}

\section{Morphology of native and microwaved starches}

Native cassava starch granules had a different morphological appearance compared to starch granules from microwaved cassava starch (Figure 1). The starch granules were mostly polygonal with some granules irregular and round in shape. The average size of the native cassava starch granules ranged between 4 and $10 \mu \mathrm{m}$, which is in the range of values (2-20 $\mu \mathrm{m})$ reported for cassava starch (Rolland-Sabaté et al., 2013; Rolland-Sabaté et al., 2012; Zhu, 2015).

Microwave heat treatment modified the surface properties of the cassava starch granules with obvious significant changes in the granule shapes and sizes. However, the addition of stearic acid to native cassava starch showed only a slight change in granule surface properties. Native cassava starch with added stearic acid had slight changes in shape, while the microwaved starch samples showed evidence of pores on the starch granules (Figure 1). The addition of stearic acid prior to microwaving or after microwaving had similar effect on starch granule morphology. Microwaving of starch has been found to alter starch structure (Lewandowicz et al., 2000) and created pin holes on granule surface (Luo et al., 2006; Oyeyinka et al., 2019).

\section{Swelling power of native and microwaved starches}

Native cassava starch showed an increase in swelling power with increase in temperature, especially (Figure
2), which may be attributed with starch gelatinization (Oyeyinka et al., 2015). Cassava starch complexed with stearic acid showed reduction in swelling at all the test temperatures compared with the native starch sample. Microwaving of starch prior to complexation with stearic acid or microwaving complexed starch resulted in further reduction in swelling of starch, indicating that microwaving further enhanced the interaction between starch and the lipids. It has been reported that reduction in swelling of starch following lipid addition results from interaction of lipids with amylose in the hydrophobic tube, which prevents starch granule hydration and swelling (Oyeyinka et al., 2017c). Furthermore, the lipid molecule may also cover starch granule surface with a film (Kim and Walker, 1992). Thus, the greater reduction in swelling after microwaving suggest that microwaving enhanced the interaction of the lipids with amylose.

\section{Pasting properties}

Native and microwave-assisted starch-stearic acid complexes showed similar pasting curves, but significantly $(\mathrm{p}<0.05)$ different pasting properties (Table 1$)$. Native and microwaved cassava starch showed reduction in the peak viscosities after stearic addition. Cassava starch containing stearic acid with subsequent microwaving showed higher reduction (approx. 19\%) in peak viscosity compared with native starch with added stearic acid (approx. 7\%) and microwaved starch with added stearic acid (approx. 9\%). The reduction in peak viscosity of starch in the presence of added lipid such as stearic acid presumably results from
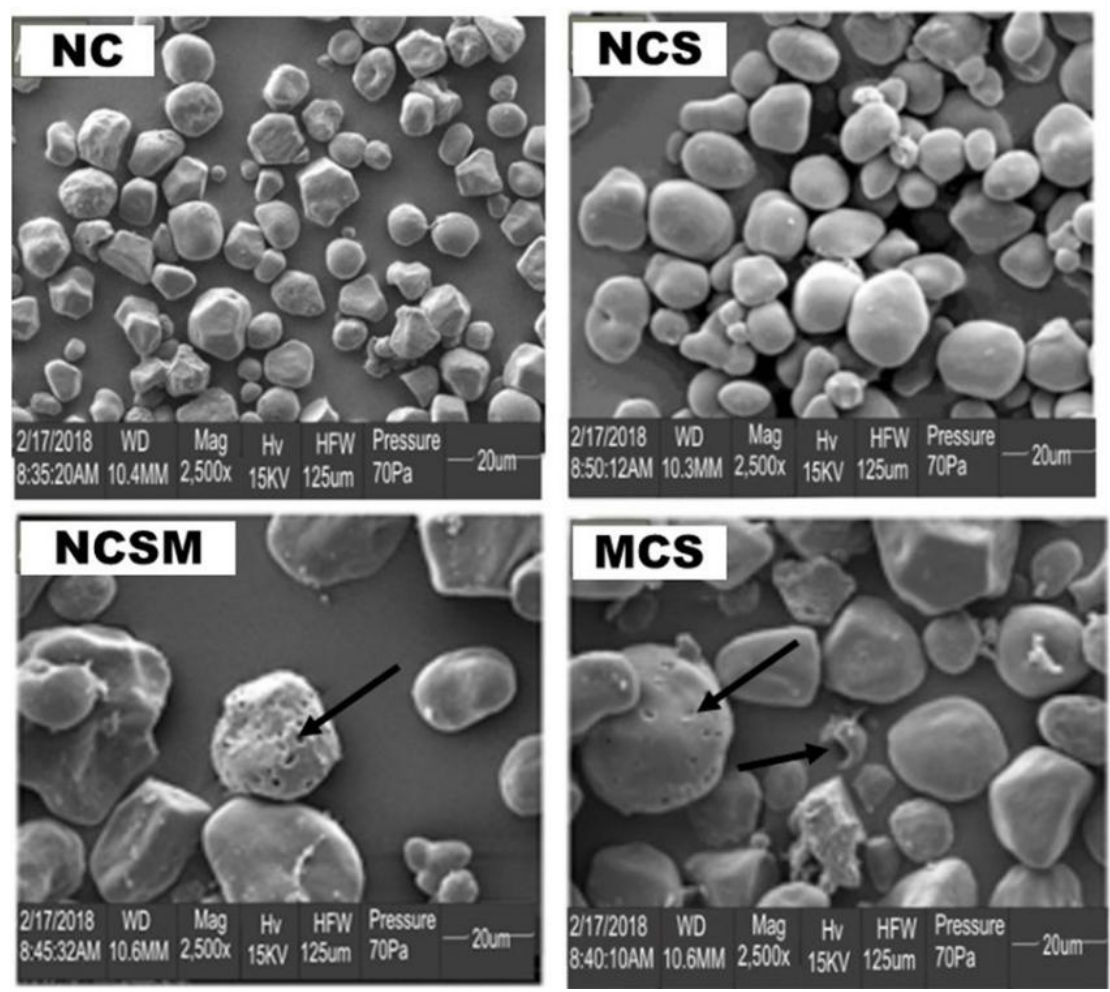

Figure 1: SEM images of native and microwave-heated starches, Scale bar represents $20 \mu \mathrm{m}$;

NC: Native cassava starch, NCS: Native cassava starch + Stearic acid, NCSM: Native cassava starch + Stearic acid + Microwave heat-treatment, MCS: Microwaved cassava starch + Stearic acid. 


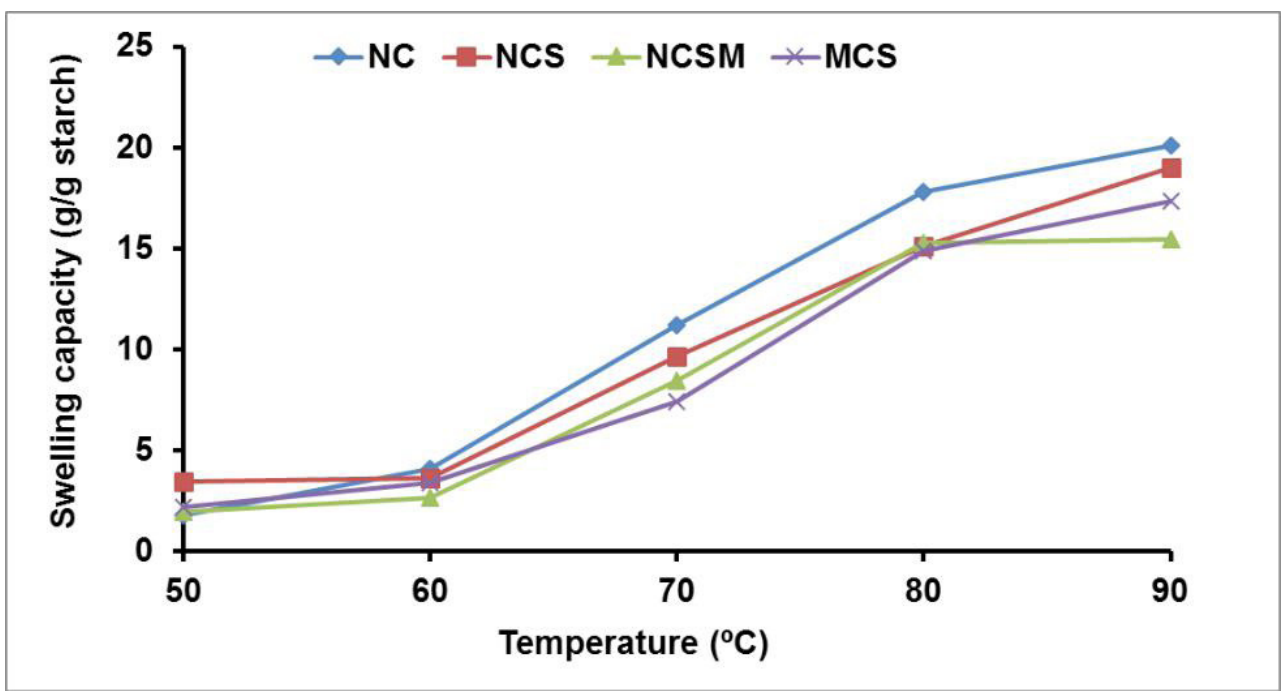

Figure 2: Swelling power of native and microwave-assisted cassava starch-stearic acid complexes.

NC: Native cassava starch, NCS: Native cassava starch + Stearic acid, NCSM: Native cassava starch + Stearic acid + Microwave heat-treatment, MCS: Microwaved cassava starch + Stearic acid.

Table 1: Pasting properties of native and cassava starches modified with microwave and stearic acid.

\begin{tabular}{|c|c|c|c|c|}
\hline Parameters & NC & NCS & MCS & NCSM \\
\hline $\mathrm{PV}$ (cP) & $2596.67 \mathrm{a} \pm 7.05$ & $2404.01_{\mathrm{a}} \pm 6.23$ & $2370.13 b \pm 2.94$ & $2111.67_{\mathrm{a}} \pm 1.41$ \\
\hline HPV (cP) & $1672.67 \mathrm{c} \pm 1.45$ & $1707.33 \mathrm{~b} \pm 1.04$ & $1654.64 \mathrm{c} \pm 4.32$ & $2049.33 \mathrm{a} \pm 2.28$ \\
\hline CPV (cP) & $2585.06 \mathrm{c} \pm 5.00$ & $2762.00 \mathrm{~b} \pm 2.00$ & $2734.00_{b} \pm 1.00$ & $3261.67_{\mathrm{a}} \pm 3.25$ \\
\hline $\mathrm{BDV}(\mathrm{cP})$ & $697.33_{b} \pm 7.68$ & $899.33_{\mathrm{a}} \pm 5.20$ & $457.00_{c} \pm 4.04$ & $354.67 \mathrm{c} \pm 4.67$ \\
\hline Setback ratio & $1.54_{\mathrm{a}} \pm 0.03$ & $1.62_{\mathrm{a}} \pm 0.17$ & $1.38 \mathrm{c} \pm 0.04$ & $1.59_{b} \pm 0.02$ \\
\hline Stability ratio & $0.71_{c} \pm 0.01$ & $0.66_{\mathrm{d}} \pm 0.01$ & $0.97_{\mathrm{a}} \pm 0.03$ & $0.85 \mathrm{~b} \pm 0.01$ \\
\hline $\mathrm{PT}\left({ }_{0} \mathrm{C}\right)$ & $74.90_{\mathrm{a}} \pm 0.20$ & $73.57_{\mathrm{a}} \pm 0.08$ & $74.17_{\mathrm{a}} \pm 0.15$ & $74.20_{\mathrm{a}} \pm 0.40$ \\
\hline Peak time (min) & $4.14_{b} \pm 0.01$ & $4.14_{b} \pm 0.04$ & $5.04_{\mathrm{a}} \pm 0.04$ & $5.04_{\mathrm{a}} \pm 0.01$ \\
\hline
\end{tabular}

Mean \pm SD. Mean with the same superscript along a row are not signifcantly different $(\mathrm{p}<0.05)$

PV: Peak viscosity; HPV: Hot paste viscosity; CPV: Cold paste viscosity; BDV: Breakdown viscosity; PT: Pasting temperature.

NC: Native cassava starch, NCS: Native cassava starch + stearic acid, NCSM: Native cassava starch + stearic acid + Microwave heat-treatment, MCS: Microwaved cassava starch + stearic acid.

the formation of amylose-lipid complex between starch and the added lipid. Previous studies similarly attributed reductions in peak viscosity to the formation of amyloselipid complexes after pasting rice starch with stearic or linoleic acids (Zhou et al., 2007) or potato starch with different fatty acids (Kawai et al., 2012).

The higher reduction in peak viscosity of cassava starch containing stearic acid with subsequent microwaving suggest that more complexes were formed between the starch and the stearic acid. This may explain why cassava starch containing stearic acid with subsequent microwaving had lower swelling power compared to other starch samples (Figure 2). With or without added stearic acid, cold paste viscosities of cassava starch were generally higher than their hot paste viscosities (Table 1). This is expected since the viscosities of biological materials are temperature dependent. However, the cold paste viscosities significantly increased with the addition of stearic acid or microwaving. Earlier studies also found increase in the final viscosity of starch after lipid addition (Maphalla and Emmambux, 2016; Obiro et al., 2012; Wang et al., 2015).

The pasting temperature $\left(74.9^{\circ} \mathrm{C}\right)$ of native cassava starch was higher than values reported for potato starch (66.2-68.6 ${ }^{\circ} \mathrm{C}$ ) (Gałkowska et al., 2014; Joshi et al., 2013). Microwaving and stearic addition did not significantly $(p<0.05)$ influence the pasting temperature of cassava starch. Native cassava starch had similar pasting temperature $\left(74.9^{\circ} \mathrm{C}\right)$ with those of the modified starch samples (average of $72.98^{\circ} \mathrm{C}$ ). Pasting temperature represents the temperature at which the starch samples will cook. Hence, it seems that microwaving cassava starch with added stearic acid or the addition of stearic acid to native starch did not significantly $(p<0.05)$ affect the pasting temperature. Setback ratio significantly reduced from 1.62 to 1.38 . The re-association 
of starch as double helices upon cooling is responsible for the setback viscosity of starches (Oyeyinka et al., 2017b) and indicates the retrogradation tendencies of starch (Liang et al., 2002). Stearic acid addition alone to native cassava showed approximately $2 \%$ reduction in setback ratio compared with stearic acid addition to microwaved cassava starch (approx. 5\%) and cassava starch containing stearic acid with subsequent microwaving (approx. 15\%). Low setback viscosity of starches is indicative of low tendencies towards retrogradation and further suggests that the presence of lipids in starch during pasting prevents the re-association of amylose chains during cooling and storage (Oyeyinka et al., 2017c).

\section{Thermal properties}

The thermal properties of microwaved cassava starch stearicacid complexes are shown in Table 2. Native cassava starch showed peak gelatinization temperature $\left(\mathrm{T}_{\mathrm{p}}\right)$ of $65.10_{\mathrm{o}} \mathrm{C}$ which is within the range $(56.2-74.7 \mathrm{oC})$ reported for cassava starch in the literature (Zhu, 2015). Modification of cassava starch with stearic acid alone or in combination with microwaving shifted the $\mathrm{T}_{\mathrm{p}}$ to a higher endotherm (92.04-101.85。C) compared with the native starch. The shift to a higher endotherm suggests that the added stearic acid possibly formed complexes with amylose in cassava starch. Lipids such as stearic acid are hydrophobic and may form inclusion complexes with amylose in starch. The amylose-lipid complexes are known to melt at varying temperature: $<80 \circ \mathrm{C}, 80-104 \circ \mathrm{C}$ and at values $>104 \circ \mathrm{C}$ (Biliaderis and Seneviratne, 1990; Raphaelides and Karkalas, 1988). These endotherms have been attributed to non-complex lipids, type I amylose-lipid complexes, and type II amyloselipid complexes respectively (Biliaderis and Seneviratne, 1990; Raphaelides and Karkalas, 1988). In this study, the addition of stearic acid to cassava starch alone or to microwaved cassava starch or to cassava starch with subsequent microwaving all formed type I amylose-lipid complexes. Previous studies reported type II amylose-lipid complex for cassava starch pasted with stearic acid and xanthan gum (Maphalla and Emmambux, 2016). The variation in the thermal stability may be due to the extended pasting time used by these authors which possibly allowed greater interaction between the starch and the stearic acid (D'silva et al., 2011).

The melting enthalpies $\left(\Delta \mathrm{H}_{\mathrm{m}}\right)$ of the modified starches varied between 0.57 and $1.07 \mathrm{~J} / \mathrm{g}$ (Table 2). Native cassava starch with added stearic acid had the lowest $\Delta \mathrm{H}_{\mathrm{m}}$, while cassava starch microwaved prior to the addition of stearic acid had the highest value. The $\Delta \mathrm{H}_{\mathrm{m}}$ provides information on the degree of order (crystallinity) in the complex and the amount of amylose-lipid complex formed (Kawai et al., 2012). Thus, the higher $\Delta \mathrm{H}_{\mathrm{m}}$ value of cassava starch microwaved prior to the addition of stearic acid suggests that more complexes were formed. The reason for this remains unclear. However, it seems that microwaving disrupts starch granular structure creating pores which may facilitate better interaction of lipids with amylose during incubation. Some authors working with annealed starch complexed with lipids similarly found that the annealed starch had pores on its surface which presumably enhanced the complexing ability of the starch (Oyeyinka et al., 2018).

\section{CONCLUSIONS}

Microwaving enhanced better complexation of amylose in cassava starch with stearic acid and improved thermal stability of the starch. The modified starch showed better functionality such as low setback viscosities and higher gelatinisation temperatures. Native or microwaved cassava starch complexed with stearic acid both produced type I amylose-lipid complexes. Cassava starch modified with microwave and stearic acid complex can potentially be used in food formulations that require high temperature for processing such as in extrusion. Further research is required to understand the interaction between starch and lipids after microwave heat-treatment. This may provide a better insight into the extent and type of fusion that governs the interaction between starch and lipids after complexation and heat treatment. In addition, the application of the modified starch in food systems should also be considered in future studies.

\section{ACKNOWLEDGEMENTS}

Authors thank West Africa Agricultural Productivity Programme (WAAPP) for supplying the cassava roots used in the study. The research was self-funded.

\section{STATEMENT OF CONFLICT OF INTEREST}

Authors declare no conflict of interest.

Table 2: Thermal properties of cassava starch-stearic acid complexes;

\begin{tabular}{lrrrl}
\hline \multicolumn{1}{c}{ Samples } & $\mathbf{T}_{\mathbf{0}}\left({ }^{\circ} \mathbf{C}\right)$ & $\left.\mathbf{T}_{\mathrm{p}}{ }{ }^{\mathbf{C}} \mathbf{C}\right)$ & \multicolumn{1}{c}{$\left.\mathbf{T}_{\mathrm{c}}{ }{ }{ }^{\mathbf{C}} \mathbf{C}\right)$} & \multicolumn{1}{c}{$\Delta \mathbf{H}_{\mathrm{m}}(\mathbf{J} / \mathbf{g})$} \\
\hline $\mathrm{NC}$ & $59.85 \mathrm{c} \pm 0.02$ & $65.10 \mathrm{c} \pm 0.82$ & $71.13 \mathrm{~b} \pm 0.20$ & $12.06 \mathrm{a} \pm 0.24$ \\
NCS & $87.66 \mathrm{~b} \pm 1.34$ & $92.04 \mathrm{~b} \pm 0.77$ & $100.22 \mathrm{a} \pm 0.14$ & $0.57 \mathrm{~d} \pm 0.04$ \\
NCSM & $92.12 \mathrm{a} \pm 0.01$ & $101.85 \mathrm{a} \pm 0.94$ & $106.95 \mathrm{a} \pm 0.61$ & $0.86 \mathrm{c} \pm 0.02$ \\
MCS & $87.82 \mathrm{~b} \pm 0.48$ & $101.40 \mathrm{a} \pm 0.60$ & $106.75 \mathrm{a} \pm 0.50$ & $1.07 \mathrm{~b} \pm 0.07$ \\
\hline
\end{tabular}

Mean with different superscript along the column are signifcantly different $(\mathrm{p}<0.05)$.

To: Onset temperature; Tp: Peak temperature; Tc: Conclusion temperature; H: Gelatinisation enthalpy

NC: Native cassava starch, NCS: Native cassava starch + Stearic acid, NCSM: Native cassava starch + Stearic acid + Microwave heat-treatment, MCS: Microwaved cassava starch + Stearic acid 


\section{REFERENCES}

Biliaderis, C., and Seneviratne, H. (1990). On the supermolecular structure and metastability of glycerol monostearate-amylose complex. Carbohydrate Polymers, 13(2): 185-206.

Chang, F., He, X., Fu, X., Huang, Q., and Jane, J.-1. (2014). Effects of Heat Treatment and Moisture Contents on Interactions Between Lauric Acid and Starch Granules. Journal of Agricultural and Food Chemistry, 62(31): 7862-7868.

Colman, T. A. D., Demiate, I. M., and Schnitzler, E. (2014). The effect of microwave radiation on some thermal, rheological and structural properties of cassava starch. Journal of Thermal Analysis and Calorimetry, 115: 2245-2252.

D’Silva, T.V., Taylor, J.R., and Emmambux, M.N. (2011). Enhancement of the pasting properties of teff and maize starches through wet-heat processing with added stearic acid. Journal of Cereal Science, 53(2): 192-197.

Gałkowska, D., Pycia, K., Juszczak, L., and Pająk, P. (2014). Influence of cassia gum on rheological and textural properties of native potato and corn starch. Starch-Stärke, 66(11-12): 1060-1070.

Joshi, M., Aldred, P., McKnight, S., Panozzo, J., Kasapis, S., Adhikari, R., and Adhikari, B. (2013). Physicochemical and functional characteristics of lentil starch. Carbohydrate Polymers, 92(2): 1484-1496.

Kaur, B., Ariffin, F., Bhat, R., and Karim, A.A. (2012). Progress in starch modification in the last decade. Food Hydrocolloids, 26(2): 398-404.

Kawai, K., Takato, S., Sasaki, T., and Kajiwara, K. (2012). Complex formation, thermal properties, and in-vitro digestibility of gelatinized potato starch-fatty acid mixtures. Food Hydrocolloids, 27(1): 228-234.

Kim, C., and Walker, C. (1992). Changes in starch pasting properties due to sugars and emulsifiers as determined by viscosity measurement. Journal of Food Science, 57(4): 1009-1013.

Lewandowicz, G., Fornal, J., and Walkowski, A. (1997). Effect of microwave radiation on physico-chemical properties and structure of potato and tapioca starches. Carbohydrate Polymers, 34(4): 213-220.

Lewandowicz, G., Jankowski, T., and Fornal, J. (2000). Effect of microwave radiation on physico-chemical properties and structure of cereal starches. Carbohydrate polymers, 42(2): 193-199.

Liang, X., King, J. M., and Shih, F.F. (2002). Pasting property differences of commercial and isolated rice starch with added lipids and $\beta$-cyclodextrin. Cereal Chemistry, 79(6): 812-818.

Lin, D., Zhou, W., Zhao, J., Lan, W., Chen, R., Li, Y., Xing, B., Li, Z., Xiao, M., and Wu, Z. (2017). Study on the synthesis and physicochemical properties of starch acetate with low substitution under microwave assistance. International Journal of Biological Macromolecules, 103: 316-326.

Luo, Z., He, X., Fu, X., Luo, F., and Gao, Q. (2006). Effect of microwave radiation on the physicochemical properties of normal maize, waxy maize and amylomaize V starches. Starch-Stärke, 58(9): 468-474.
Maphalla, T.G., and Emmambux, M.N. (2016). Functionality of maize, wheat, teff and cassava starches with stearic acid and xanthan gum. Carbohydrate Polymers, 136: 970-978.

Meng, S., Ma, Y., Cui, J., and Sun, D.W. (2014a). Preparation of corn starch-fatty acid complexes by high-pressure homogenization. Starch-Stärke, 66(910): 809-817.

Meng, S., Ma, Y., Sun, D.-W., Wang, L., and Liu, T. (2014b). Properties of starch-palmitic acid complexes prepared by high pressure homogenization. Journal of Cereal Science, 59(1): 25-32.

Nwokocha, L.M., Aviara, N. A., Senan, C., and Williams, P.A. (2009). A comparative study of some properties of cassava (Manihot esculenta, Crantz) and cocoyam (Colocasia esculenta, Linn) starches. Carbohydrate Polymers, 76(3): 362-367.

Obiro, C., Ray, S., and Emmambux, M. (2012). Occurrence of amylose-lipid complexes in teff and maize starch biphasic pastes. Carbohydrate Polymers, 90(1): 616622.

Osunsami, A., Akingbala, J., and Oguntimein, G. (1989). Effect of storage on starch content and modification of cassava starch. Starch-Stärke, 41(2): 54-57.

Oyeyinka, S.A., Adegoke, R., Oyeyinka, A.T., Salami, K.O., Olagunju, O.F., Kolawole, F. L., Joseph, J.K., and Bolarinwa, I.F. (2018). Effect of annealing on the functionality of Bambara groundnut (Vigna subterranea) starch-palmitic acid complex. International Journal of Food Science \& Technology, 53(2): 549-555.

Oyeyinka, S.A., and Oyeyinka, A.T. (2018). A review on isolation, composition, physicochemical properties and modification of Bambara groundnut starch. Food Hydrocolloids, 75: 62-71.

Oyeyinka, S.A., Singh, S., Adebola, P.O., Gerrano, A.S., and Amonsou, E. O. (2015). Physicochemical properties of starches with variable amylose contents extracted from bambara groundnut genotypes. Carbohydrate Polymers, 133: 171-178.

Oyeyinka, S.A., Singh, S., and Amonsou, E.O. (2017a). Physicochemical and Mechanical Properties of Bambara Groundnut Starch Films Modified with Stearic Acid. Journal of Food Science, 82(1): 118-123.

Oyeyinka, S.A., Singh, S., and Amonsou, E.O. (2017b). Physicochemical properties of starches extracted from bambara groundnut landraces. Starch-Stärke, 69 (3-4): 1600089.

Oyeyinka, S.A., Singh, S., Ma, Y., and Amonsou, E.O. (2016a). Effect of high-pressure homogenization on structural, thermal and rheological properties of bambara starch complexed with different fatty acids. RSC Advances, 6(83): 80174-80180.

Oyeyinka, S.A., Singh, S., Ma, Y., and Amonsou, E.O. (2016b). Influence of high-pressure homogenization on the physicochemical properties of bambara starch complexed with lysophosphatidylcholine. LWT-Food Science and Technology, 74: 120-127.

Oyeyinka, S.A., Singh, S., Venter, S.L., and Amonsou, E.O. (2017c). Effect of lipid types on complexation and some physicochemical properties of bambara groundnut starch. Starch-Stärke, 69(3-4): 1600158. 
Oyeyinka, S.A., Umaru, E., Olatunde, S.J., and Joseph, J.K. (2019). Effect of short microwave heating time on physicochemical and functional properties of Bambara groundnut starch. Food Bioscience, 28: 36-41.

Raphaelides, S.N., and Karkalas, J. (1988). Thermal dissociation of amylose-fatty acid complexes. Carbohydrate Research, 172(1): 65-82.

Rolland-Sabaté, A., Sanchez, T., Buléon, A., Colonna, P., Ceballos, H., Zhao, S.-S., Zhang, P., and Dufour, D. (2013). Molecular and supra-molecular structure of waxy starches developed from cassava (Manihot esculenta Crantz). Carbohydrate Polymers, 92(2): 1451-1462.

Rolland-Sabaté, A., Sánchez, T., Buléon, A., Colonna, P., Jaillais, B., Ceballos, H., and Dufour, D. (2012). Structural characterization of novel cassava starches with low and high-amylose contents in comparison with other commercial sources. Food Hydrocolloids, 27(1): 161-174.

Schmidt, V.C.R., Porto, L.M., Laurindo, J.B., Menegalli, F.C. (2013). Water vapor barrier and mechanical properties of starch films containing stearic acid. Industrial Crops and Products, 41: 227-234.

Stevenson, D.G., Domoto, P.A., and Jane, J.-1. (2006). Structures and functional properties of apple (Malus domestica Borkh) fruit starch. Carbohydrate Polymers, 63(3): 432-441.

Varavinit, S., Chaokasem, N., and Shobsngob, S. (2001). Studies of flavor encapsulation by agents produced from modified sago and tapioca starches. StarchStärke, 53(6): 281-287.

Wang, S., Wang, J., Yu, J., and Wang, S. (2015). Effect of fatty acids on functional properties of normal wheat and waxy wheat starches: a structural basis. Food Chemistry, 190: 285-292.

Zhao, K., Li, B., Xu, M., Jing, L., Gou, M., Yu, Z., Zheng, J., and Li, W. (2018). Microwave pretreated esterification improved the substitution degree,

structural and physicochemical properties of potato starch esters. LWT-Food Science and Technology, 90: 116-123.

Zhou, Z., Robards, K., Helliwell, S., and Blanchard, C. (2007). Effect of the addition of fatty acids on rice starch properties. Food Research International, 40(2): 209-214.

Zhu, F. (2015). Composition, structure, physicochemical properties, and modifications of cassava starch. Carbohydrate Polymers, 122: $456-480$ 